Asia Pacific Journals

\title{
A DECISION-MAKING MODEL FOR GREEN MANUFACTURING USING ANALYTICAL HIERARCHY PROCESS AND GREY RELATION GRADING
}

\begin{tabular}{|c|c|c|c|}
\hline $\begin{array}{l}\text { Abhishek Kumar } \\
\text { Singh }^{1}\end{array}$ & Sanjay Kumar Jha $^{2}$ & Anand Prakash ${ }^{3}$ & $\begin{array}{l}\text { Shubhanshu Shekhar } \\
\text { Shukla }^{4}\end{array}$ \\
\hline $\begin{array}{l}\text { Department of } \\
\text { Production Engineering. } \\
\text { Institute of Technology, } \\
\text { Deoghar, India }\end{array}$ & $\begin{array}{l}\text { Department of } \\
\text { Production Engineering. } \\
\text { Birla Institute of } \\
\text { Technology, Mesra, } \\
\text { Ranchi }\end{array}$ & $\begin{array}{l}\text { School of General } \\
\text { Management. } \\
\text { National Institute of } \\
\text { Construction } \\
\text { Management and } \\
\text { Research, Pune, India }\end{array}$ & $\begin{array}{l}\text { Byju's Classes. } \\
\text { Byju's Classes, New Delhi, } \\
\text { India }\end{array}$ \\
\hline
\end{tabular}

\begin{abstract}
This paper applies two popular multiple criteria decision making (MCDM) techniques, namely, analytic hierarchy process and gray relational grading aimed to supporting decision makers who are faced with conflicting alternatives of green manufacturing to make an optimal decision. To achieve this purpose the paper analyzes three different industries in the perspective of green manufacturing and consequently finds the best among them with the help of relation matrix which is based on analytical hierarchy process and grey relation theory. Three different industries selected for the study are corrugated paper, enamel utensils and exhaust mufflers. The paper analyses the green manufacturing measures in accordance with applicable decisive factors like green product design, green design of raw material, green process, green technology, green packaging material and green packaging design. The study has presented combined MCDM approach with the corrugated paper having maximum grey relation grade.
\end{abstract}

Keywords-Analytical Hierarchy Process (AHP); DecisionMaking Model; Green Manufacturing; Grey Relation.

\section{INTRODUCTION}

Manufacturing operations are an integral part of any industry. An important concern in present context is to reduce the adverse environmental impacts caused by different manufacturing operations. There are several models and methodologies proposed by different researchers on adoption of green manufacturing practices (see Rusinko, 2007). Such practices have intent towards environmental friendliness. The use of grey relation grading (Deng, 1982) and AHP (Satty, $1980 ; 1990)$ helps to make correction in resultant weights to be assigned for green manufacturing priorities in relatively less time. This paper studies theory and method of green manufacturing practices followed in industries like corrugated paper units, enamel utensil units and exhaust mufflers units on the basis of AHP followed by grey theory to establish a priority among factors to observe their authenticity and effectiveness according to the hierarchical model shown in Fig 1 (see, for example, Singh et al., 2014).
Factors of green manufacturing proposed by Singh et al. (2015) are green product design, green design of raw materials, green process, green technology, green packaging material, and green packaging design (see Fig 1). Green product design includes eco-impact during product life cycle and compatibility with living environment. Green design of raw materials comprises of ease of acquisition, ease of replacement and ease of simplification. Green process is constituted of processes to reduce wastes and process to recycle materials and process to use re-manufacturing. Green technology includes environmental improvement of production, technical innovation capabilities and comprehensiveness of eco standard test reports. Green packaging material includes application of eco-materials for packaging and recovery rate of packaging material. Green packaging design comprises of reusable packaging and integration of eco marks into packaging design.

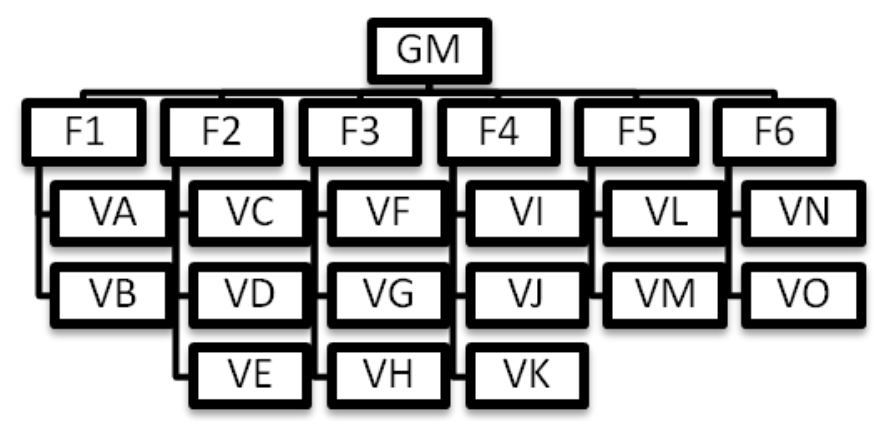

Fig 1: Green Manufacturing Evaluation System

\section{SELECTION OF INDUSTRY}

Three different industries like corrugated paper (I1), enamel utensils (I2) and exhaust mufflers (I3) have been selected from an exhaustive list of small scale industries based on the criteria that the processes and factors of green manufacturing can be utilized to a great extent in these three cases. These industries 


\section{Asia Pacific Journals}

have been selected for applying grey relation theory and for these operations a standard reference set is created. The industries were ranked on a scale of 1-9 on the basis of their performances of stated factors and thus a matrix was created as shown in Table 1. This matrix has been used for AHP calculations.

Table 1: Detailed Information on Industries Inspected for Green Manufacturing

\begin{tabular}{|c|c|c|c|}
\hline Industry & Il & I2 & I3 \\
\hline VA & 6 & 5 & 3 \\
\hline VB & 9 & 4 & 3 \\
\hline VC & 8 & 6 & 7 \\
\hline VD & 7 & 7 & 4 \\
\hline VE & 8 & 7 & 3 \\
\hline VF & 7 & 6 & 8 \\
\hline VG & 9 & 3 & 9 \\
\hline VH & 8 & 4 & 8 \\
\hline VI & 7 & 5 & 8 \\
\hline VJ & 6 & 4 & 8 \\
\hline VK & 5 & 5 & 5 \\
\hline VL & 9 & 8 & 4 \\
\hline VM & 9 & 7 & 3 \\
\hline VN & 7 & 6 & 3 \\
\hline VO & 8 & 7 & 2 \\
\hline
\end{tabular}

The selected industries were graded according to factors of green manufacturing (GM), say, green product design (F1), green design of raw materials $(\mathrm{F} 2)$, green process $(\mathrm{F} 3)$, green technology (F4), green packaging material (F5), and green packaging design (F6). Green product design includes ecoimpact during product life cycle (VA) and compatibility with living environment (VB). Green design of raw materials comprises of ease of acquisition (VC), ease of replacement (VD) and ease of simplification (VE).Green process is constituted of processes to reduce wastes (VF), process to recycle materials (VG) and process to use re-manufacturing (VH).Green technology includes environmental improvement of production (VI), technical innovation capabilities (VJ) and comprehensiveness of eco standard test reports (VK).Green packaging material includes application of eco-materials for packaging (VL) and recovery rate of packaging material (VM).Green packaging design comprises of reusable packaging $(\mathrm{VN})$ and integration of eco marks into packaging design (VO).

\section{ANALYTICAL HIERARCHY PROCESS (AHP)}

AHP is a systematic procedure for representing the elements of any problem hierarchically. The pair wise comparison matrix is of size $n \times n$, where $n$ is the number of elements to be compared pair wise as shown in Table 2. The matrix will be filled up accordingly using following procedures Satty (1980):

a. Each element compared with itself will get a value 1 i.e. $\mathrm{a}(1,1)=\mathrm{a}(2,2)=\ldots \mathrm{a}(\mathrm{n}, \mathrm{n})=1$.

b. When ith element is compared with jth element, it has got a value $A(I, j)$, jth element being compared with ith element has got a value $\mathrm{a}(\mathrm{I}, \mathrm{j})=1 / \mathrm{a}(1,2), \mathrm{a}(3,1)=$ $1 / \mathrm{a}(1,3) \ldots \ldots . \mathrm{a}(\mathrm{n}, 1)=1 / \mathrm{a}(1, \mathrm{n})$

c. Relative Weight $(\mathrm{RW})=$ $\mathrm{a}(1,1) \times \mathrm{a}(2,1) \times \mathrm{a}(3,1) \times \mathrm{a}(4,1) \times \mathrm{a}(5,1) n n$

d. Normalized Weight $(\mathrm{NW})=\mathrm{RW} / \Sigma \mathrm{RW}$

e. Maximum Eigen Value $(\lambda)=\Sigma$ column $\mathrm{A} \times \mathrm{NW}$ value row $\mathrm{A}+=\Sigma$ column $\mathrm{B} \times \mathrm{NW}$ value row $\mathrm{B}+\ldots \ldots .+=$

$\Sigma$ column $\mathrm{n} \times \mathrm{NW}$ value row $\mathrm{n}$

f. Consistency Index $(\mathrm{CI})=(\lambda-\mathrm{n}) /(\mathrm{n}-1)$

g. Random Index $(\mathrm{RI})=1.98 \times(\mathrm{n}-2) / \mathrm{n}$

h. Consistency Ratio $(\mathrm{CR})=\mathrm{CI} / \mathrm{CR}$, should be within 10 percent

i. Composite rank $(\mathrm{COR})=\mathrm{NW}$ Parameter 1 weightage $x$ NW of that Parameter + NW Parameter 2 weightage $x$ NW of that Parameter $+\ldots \ldots .+$ NW Parameter $n$ weightage $\times \mathrm{NW}$ of that Parameter.

Table 2: The AHP matrix

\begin{tabular}{|c|c|c|c|c|c|}
\hline 1 & 1 & 3 & 2 & 3 & 2 \\
\hline 1 & 1 & 2 & 3 & 3 & 4 \\
\hline $1 / 3$ & $1 / 2$ & 1 & 2 & 4 & 3 \\
\hline $1 / 2$ & $1 / 3$ & $1 / 2$ & 1 & 3 & 2 \\
\hline $1 / 3$ & $1 / 3$ & $1 / 4$ & $1 / 3$ & 1 & 3 \\
& & & & & \\
\hline $1 / 2$ & $1 / 4$ & $1 / 3$ & $1 / 2$ & $1 / 3$ & 1 \\
\hline
\end{tabular}

Consistency check $=$ 


\section{Asia Pacific Journals}

\section{DETERMINATION OF WEIGHTS USING AHP}

For calculation of weights, we utilized the concept of AHP, thus in the process obtaining the weights for respective factors according to their importance in the process of green manufacturing. The weights are as follows:

\begin{tabular}{|l|l|}
\hline 1 & 1 \\
\hline 1 & 1 \\
\hline
\end{tabular}

Weights: $0.75,0.25$

\begin{tabular}{|c|c|c|}
\hline 1 & 3 & 2 \\
\hline $1 / 3$ & 1 & $1 / 3$ \\
\hline $1 / 2$ & 3 & 1 \\
\hline
\end{tabular}

Weights: $0.527,0.139,0.332$

\begin{tabular}{|c|c|c|}
\hline 1 & 1 & 3 \\
\hline 1 & 1 & 6 \\
\hline $1 / 3$ & $1 / 6$ & 1 \\
\hline
\end{tabular}

Weights: 0.396, 0.499, 0.104

\begin{tabular}{|c|c|c|}
\hline 1 & 3 & 5 \\
\hline $1 / 3$ & 1 & 1 \\
\hline $1 / 5$ & 1 & 1 \\
\hline
\end{tabular}

Weights: $0.658,0.185,0.156$

\begin{tabular}{|c|c|}
\hline 1 & 4 \\
\hline $1 / 4$ & 1 \\
\hline
\end{tabular}

Weights: $0.8,0.2$

\begin{tabular}{|c|c|}
\hline 1 & 5 \\
\hline $1 / 5$ & 1 \\
\hline
\end{tabular}

Weights: $0.833,0.166$

\section{GREY RELATION PRINCIPLE}

Grey relation analysis belongs to grey system theory put forward by Professor Deng Ju-long in 1982 and it mainly researches quantification analysis problem of system state development. Hossein et al. (2012) in grey relation theory states, the geometry curve constructed by several statistical data is more similar, the relation degree is bigger. In Fig 2, the similarity degree of curve one and two is greater than similarity degree of curve one and three, and the relation degree of curve one and two is more than curve of one and three.

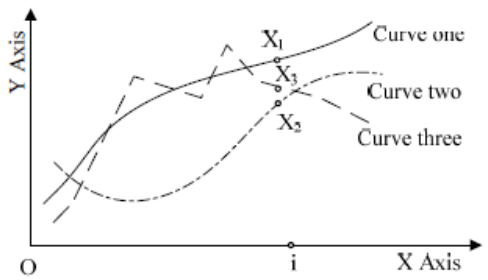

Fig 2: Grey Relation Curve

The relation sequence reflects approximate sequence of each project to objective project, and the project of maximal grey relation degree is best one. For standard reference sequence $\mathrm{x} 0=[\mathrm{x} 01, \mathrm{x} 02, \ldots, \mathrm{x} 0 \mathrm{n}], \mathrm{xi}=[\mathrm{xi} 1, \mathrm{xi} 2, \ldots, \mathrm{xin}](\mathrm{i}=1,2, \ldots, \mathrm{m})$ is regarded as compared sequence, and the grey relation coefficient matrix is defined as following:

$$
\begin{gathered}
\Delta \min =\min _{\mathrm{i}} x \\
\Delta \max =\max _{i} m \\
\Delta i k=\|_{i k}-x_{\text {ok }} \mid(i=1,2, \ldots, m ; k=1, \tilde{i}
\end{gathered}
$$

" $\sigma$ " is distinguishing coefficient, and it shows importance degree of unity in relation space. According to grey relation literature research, grey relation coefficient is monotone increasing function, and its principle is shown as following. The comparison mean of relation space is defined as

$$
\bar{\Delta}=\sum_{i=1}^{m} \sum_{k=1}^{n} \mid x_{0 k}-
$$

The scale coefficient of mean is $\gamma=$

(1) If $>3$, then

(When there is abnormal value in comparing set, is very big. Parameter hence should be taken smaller value to weaken influence of $\max )$.

(2) If $\max <3$ then

(When comparing set is stable, max is small. Parameter hence should be taken bigger value to increase relation degree unity).

The relation coefficient for each comparison sequence can be determined by Equation (5), and is weight of each item in comparison set. What' more, is grey relation coefficient for each comparison sequence.

$C_{\mathrm{i}}=W_{\mathrm{i}} \times H_{\mathrm{i}}$

After the grey relation coefficient id established, the correlation between the various industries is further done by establishing the grey relation grade, given by the formula below:

$\tau_{i}=\sum_{j=1}^{k} \beta_{j} \gamma_{i} \quad \sum_{j=1}^{k} \beta_{j}=1$ 


\section{Asia Pacific Journals}

\section{RESULTS}

For establishing the grey relation theory, the standard reference set according to the evaluation goal is pre treated Kleindorfer (2005); Porter \& Van der Linde (1995). The evaluation indexes can be divided into two types:

1) The smaller the value is the better it will be. The formula for this case is as follows:

2) The bigger the value is better it will be. The formula for this case is as follows:

From the above two formulas we deduced the first grade difference matrix shown in Table 3:

$\mathrm{P}=\{\mathrm{P} 1, \mathrm{P} 2, \mathrm{P} 3, \mathrm{P} 4, \mathrm{P} 5, \mathrm{P} 6\}=$

Table 3: First Grade Difference matrix

\begin{tabular}{|l|l|l|l|l|l|}
\hline $0.08,0:$ & $0,0,0:$ & $\begin{array}{l}0 . .047,0, \\
0:\end{array}$ & $\begin{array}{l}0.005,0 . \\
11,0:\end{array}$ & 0,0 & $: 0,0$ \\
\hline $0.071,0$. & $0.095,0,0.0$ & $0.095,0$. & $0.15,0.2$ & 0.0476, & $: 0.0625$ \\
$3125:$ & $55:$ & $28,0.2:$ & $2,0:$ & 0.105 & 0.06 \\
\hline $0.2142,0$ & $0 . .047,0.01$ & $0,0,0:$ & $0,0,0:$ & $0.24,0$. & $: 0.25,0$ \\
$.375:$ & $67,0.277:$ & & & 316 & 353 \\
\hline
\end{tabular}

\begin{tabular}{|c|c|c|c|c|c|}
\hline $1.0,1.0:$ & $1.0,01.0,1.0 \ldots$ & $0.689,1,1.0$ & $\begin{array}{l}0.628,0.84 \\
9.1:\end{array}$ & $1.0,1.0$ & $1.0,1.0$ \\
\hline $0.85,0.408$ & $\begin{array}{l}0.524,1.0,0.90 \\
5:\end{array}$ & $\begin{array}{l}0.8789,0.758,0 . \\
7913:\end{array}$ & $\begin{array}{l}0.849,0.79 \\
4,1:\end{array}$ & $\begin{array}{l}0.040,0.0 \\
058\end{array}$ & $\begin{array}{l}0.7699,0.9 \\
277\end{array}$ \\
\hline $\begin{array}{l}0.799,0.68 \\
05:\end{array}$ & $\begin{array}{l}0.950 \\
0.850,0.754\end{array}$ & $1,1,1$ : & $1.0,1 \cdot 0,1.0$ & $\begin{array}{l}0.074,0.0 \\
29\end{array}$ & $\begin{array}{l}0.7877,0.69 \\
05\end{array}$ \\
\hline
\end{tabular}

$\mathrm{H}=(\mathrm{H} 1, \mathrm{H} 2, \mathrm{H} 3, \mathrm{H} 4, \mathrm{H} 5, \mathrm{H} 6\}$

According to equation

Grey relation coefficient is:

, i.e. $\{1,2,3\}$

$\mathrm{C}=\left\{\mathrm{C}_{1} \mathrm{C}_{2} \mathrm{C}_{3}\right\}=$

\begin{tabular}{|l|l|l|l|l|l|}
\hline 1.0 & 0.998 & 0.875 & 0.726 & 1 & 0.99 \\
\hline 0.7395 & 0.7065 & 0.808 & 08615 & 0.033 & 0.795 \\
\hline 0.769 & 0.744 & 0.99 & 0.99 & 0.065 & 0.766 \\
\hline
\end{tabular}

Now, the grey relation grade is established according to the formula given below:

According to definition of relation space comparison mean,

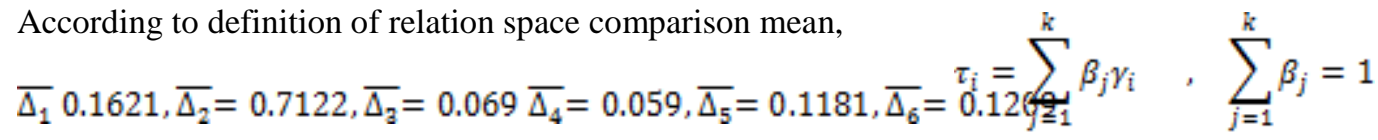

In terms of equation (2) and (3), the maximum and minimum value of each first grade evaluation index respectively is:

$$
\begin{gathered}
\Delta \min _{1}=\Delta \min _{2}=\Delta \min _{\mathrm{a}}=\Delta \min _{4}=\Delta \min _{5}=\Delta \min n_{6}=0 \\
\Delta \max _{1}=0.2142 ; \Delta \max _{2}=0.27: 0.28 \\
\Delta \max _{4} 0.316
\end{gathered}
$$

The scale coefficient of mean is / , thus,

$$
0.2681 ; \quad 0.3737 ; \quad 0.3425
$$

The Distinguishing coefficients are:

$$
\sigma_{1}=1.006 ; \sigma_{2}=0.3785 ; \sigma ;
$$

$$
0.566 ; \quad 0.5925
$$

First grade relation matrix can be obtained by equation (1) is shown in Table 4:
The resultant grey relation grade matrix is as follows:

\begin{tabular}{|l|}
\hline 0.939409 \\
\hline 0.7234545 \\
\hline 0.894263 \\
\hline
\end{tabular}

From the above table, the corrugated paper box industry has maximum grey relation grade, thus showing that it is the best among the industries considered.

\section{VII.CONCLUSION}

The grey system theory is based on the assumption that the system of green manufacturing is uncertain and that the information regarding the system is insufficient to build a relational analysis or to construct a model. The grey theory has presented a grey relation space and identified that the corrugated paper box industry has maximum grey relation grade. By means of the ranking orders produced by the grey relation model in conjunction with AHP, we can get a clear but differentiating picture of green manufacturing priority in different industry. Our suggested application strengthens the quantitative analysis capacity of grey relation models making them more generalized for fitting a practical behavioral priority. 


\section{Asia Pacific Journals}

\section{References}

[1] Satty, T. L, The Analytical Hierarchy Process, McGraw Hill, New York, 1980.

[2] Satty. T. L. "How to make decision - AHP", Euro J Operat Res, Vol. 48 (1990), pp. 9-26.

[3] Hossein H, Somayeh A T, Ghafour A. "Grey Relational Analysis to Determine the OptimumProcess Parameters for Open-End Spinning Yarns", Journal of Engineered Fibers and Fabrics,Vol. 7 No. 2 (2012), pp.81-86.

[4] Singh A. K., Shukla, S. S., \& Dutta J. "Green Manufacturing: Case Study using AHP and Grey Relation", International Journal of Engineering and Applied Sciences, Vol. 2 No. 3 (2015), pp.83-86.

[5] Singh A. K., Jha S. K., \&Prakash, A. "Green Manufacturing (GM) Performance Measures: An Empirical Investigation from Indian MSMEs",International Journal of Research in Advent Technology, Vol. 2 No. 4 (2014), pp 51-65.

[6] Kleindorfer, P. R., Singhal, K., \& van Wassenhove, L. N. "Sustainable operations management", Production and Operations Management, Vol. 14 No. 4 (2005), pp. 482-492. http://dx.doi.org/10.1111/j.19375956.2005.tb00235.x

[7] Porter, M. E., \& van der Linde, C. "Green and competitive",Harvard Business Review, Vol. 73 No. 5(1995), pp. 120-134.

[8] Rusinko, C. A. "Green Manufacturing: An Evaluation of Environmentally Sustainable Manufacturing Practices and Their Impacts oncompetitive outcomes", IEEE, Vol.5, No.3 (2007). 